\author{
MARISOL JORDÁN \\ OLGA BEHAR \\ SANDRO BUITRAGO \\ JOHANA CASTILLO
}

Universidad Santiago de Cali (Cali, Colombia)

\title{
Estrategias educomunicativas para fortalecer procesos de resocialización de un grupo de adolescentes infractores en Cali ${ }^{*}$
}

El fenómeno de la violencia en adolescentes es una de las problemáticas que afrontan las grandes ciudades a nivel global. En Santiago de Cali se aglutinan decenas de miles de jóvenes envueltos en diferentes y complejas problemáticas generadas desde sus propios contextos familiares, sociales y educativos; por eso la ciudad se ha visto impelida a desarrollar diferentes estrategias de trabajo para amortiguar el índice delincuencial juvenil.

Acorde con las políticas estatales, y en línea con los planteamientos de la Comunicación sobre la incidencia de estrategias educomunicativas en procesos de resocialización, surge el proyecto de investigación «Estrategias Educomunicativas para la resocialización de adolescentes infractores del Centro de Formación Juvenil Buen Pastor (Cali)». Esta iniciativa comenzó hace tres años entre estudiantes del curso de periodismo social de la Facultad de Comunicación y Publicidad de la Universidad Santiago de Cali -USC-, que trabajan de la mano con la ONG Crecer en Familia, entidad operadora del Centro de Formación Juvenil Buen Pastor-CFJBP-, con el fin de implementar la estrategia que han denominado «Plan Padrino».

\footnotetext{
* Artículo de reflexión desde la línea temática de Modelos educativos que promueven modalidades de apropiación de conocimientos (medios comunitarios y emergentes). El presente artículo refiere la experiencia de la investigación "Estrategia educomunicativa como herramienta de intervención para los procesos de resocialización de adolescentes infractores recluidos en el Centro de Formación Juvenil Buen Pastor (Cali)", desarrollada entre 2014 y 2016.
} 
La investigación se inició con el objetivo de diseñar e implementar estrategias de trabajo con los menores infractores en las que la educomunicación tuviera un papel central en los procesos de resocialización. El artículo presenta las diferentes fases de desarrollo del proyecto, al igual que las herramientas educomunicativas utilizadas. Se expone también el contexto en el que se inscribe el proyecto, el proceso de diagnóstico para el diseño de la estrategia, y los resultados de su implementación, destacando las herramientas educomunicativas utilizadas en los espacios de trabajo con los adolescentes infractores, y la forma en que los estudiantes universitarios asumieron su papel como tutores de los procesos educativos.

\section{Menores infractores, un problema de grandes proporciones}

El informe presentado por el Instituto Colombiano de Bienestar Familiar -ICBF-, en septiembre de 2013, muestra que alrededor de 18.559 menores de edad ingresaron al Sistema de Responsabilidad Penal para Adolescentes, mientras que en 2012 fueron 29.457; y en 2011, 27.309.

En el balance publicado por el Periódico El País (15 de enero de 2014), se evidenció que en la capital del Valle fueron aprehendidos 2.439 menores (más de la mitad que en Bogotá, que tuvo 3.253 casos). La cifra alarma, dado que la capital de Colombia triplica la población caleña. Más grave fue detectar que "los menores fueron detenidos en su gran mayoría por hurto. También por fabricación, tráfico, porte o tenencia de armas de fuego; de estupefacientes y por homicidio, entre otros delitos".

En 2015, el diagnóstico seguía presentado una situación compleja, pues ningún programa de resocialización en los Centros de Formación, ni de intervención psicosocial, en los escenarios de violencia, parecía haber mejorado la problemática. Un informe publicado por el periódico El Tiempo (18 de septiembre de 2015), «En cinco años van más de 50.000 menores detenidos por microtráfico», evidenció que el fenómeno social en crecimiento de la delincuencia juvenil ha obligado a transformar el marco jurídico para la atención de estos asuntos. Así lo plantean también los investigadores Fernando Mayorga y Olga Yamile Tolosa, de la Universidad de Manizales:

Según el ICBF, se estima que desde que el Sistema empezó a implementarse en el país, más de 133.0oo adolescentes han sido sancionados por infringir la Ley [...] En Colombia la Ley de Infancia y Adolescencia (ley 1098) entró en vigencia en marzo de 2007 y se aplicó inicialmente en Bogotá y Cali, por presentar altas cifras de delincuencia juvenil. A partir de su aplicación, los infractores de 14 a 18 años son obligados a responder por sus acciones; es decir, que cuando un menor es capturado se le hace todo el proceso y dependiendo de la gravedad del delito el Juez de Infancia y Adolescencia lo sanciona -en ocasiones- con privación de la libertad y reclusión en un Centro de Formación (Villabona, 2014). 
Pese a los esfuerzos por desarrollar procesos de resocialización y reeducación en los adolescentes a través de estrategias pedagógicas, formativas y restaurativas, implementadas en el marco del sistema de responsabilidad penal, aún se requiere mayor compromiso del Estado y de la sociedad para abordar una problemática tan delicada. Dentro de ese compromiso, está el papel fundamental de los medios de comunicación, cuya responsabilidad ha sido brindar información sobre los hechos; sin embargo, su enfoque siempre ha estado centrado en las noticias negativas.

«Menores infractores viven en condiciones indignas», «Buscan endurecer sanciones penales a adolescentes infractores», «Motín en centro transitorio de menores», «Jueces de menores infractores en Cali se declaran en Plantón», «Con orines protestan menores infractores en Cali», «Buscan menores infractores que fugaron de Centro de reclusión en Cali», «Cupos para menores infractores, problemática que se desborda en el Valle» (El País, 2014, 2015).

Estos titulares de prensa muestran cómo la agenda informativa aborda lo negativo y deja de lado aquellas expresiones positivas que los procesos de resocialización gestan en muchas de las instituciones que atienden a estos grupos de población.

Ante la ausencia de espacios para visibilizar esos otros sucesos, que a ojos del periodismo tradicional podrían ser poco noticiables, emerge la necesidad de aprovechar los medios menos comerciales, menos conocidos y quizá menos condicionados a la necesidad de captar públicos con información sensacionalista, para mostrar la otra cara de las historias, la que construyen quienes viven cada circunstancia y pueden, con conocimiento de causa, dar su propia versión.

Todo esto impulsó la implementación del proyecto de investigación relacionado en el presente artículo, iniciativa enmarcada en los conceptos de educomunicación e investigación-acción participativa como herramientas para el cambio social. En este caso, a través de experiencias que permitan a los jóvenes reflexionar sobre sus acciones y encaminar sus proyectos de vida lejos de las actividades delincuenciales.

\section{Metodología}

Para desarrollar el proyecto entre la USC y el Centro Buen Pastor se consideraron los aspectos ya relacionados y se determinó la investigación tipo IAP (InvestigaciónAcción Participativa) que permite una aproximación a la realidad de los adolescentes infractores del Buen Pastor, especialmente en la intención inicial de diagnosticar las competencias mediáticas y las condiciones institucionales para el desarrollo de actividades comunicativas. 
Los resultados del diagnóstico fueron el marco de referencia para el diseño de la estrategia educomunicativa y su posterior implementación con el grupo de interés. Consideramos que la IAP fue apropiada para los propósitos propuestos, dado que permitió combinar los procesos de conocimiento y accionar de los participantes, permitiendo que, tanto los estudiantes del programa de Comunicación Social de la USC, como los internos en el Buen Pastor pudieran comprender mejor la realidad, posibilitando el aprendizaje y creando un ambiente de construcción colectiva para el mejoramiento continuo.

La metodología de la investigación-acción participativa se desarrolla usualmente en tres fases:

1. Observación participante: el investigador se involucra en la realidad que se estudiará, se relaciona con los actores y participa en los procesos.

2. Investigación participativa: se diseña la investigación y se eligen sus métodos basados en el trabajo colectivo, la utilización de elementos de la cultura popular y la recuperación histórica.

3. Acción participativa: implica transmitir la información obtenida al resto de la comunidad; el investigador presenta diversos métodos disponibles para recolectar y socializar la información.

Para efectos de este proyecto las tres fases se denominaron: Reflexión crítica; Intervención a través de la acción; Participación.

\section{Resultados}

\section{Estudio de caso. Adolescentes infractores en Cali}

En julio de 2013 se estableció el convenio con la Fundación ONG Crecer en Familia, entidad operadora del CFJBP, lugar de reclusión de un porcentaje importante de adolescentes infractores en la ciudad de Cali. Mediante este convenio se desarrolló un proyecto con 30 estudiantes de la facultad de Comunicación y Publicidad de la Universidad Santiago de Cali, provenientes de las áreas de periodismo escrito, radial y audiovisual, con el fin de desarrollar estrategias pedagógicas en comunicación para buscar espacios que contribuyan a la resocialización de menores de edad que pasan por situaciones de agresividad, rebeldía y desesperanza, mientras cumplen con las sanciones impuestas por la justicia, debido a los crímenes que han cometido.

Por otro lado, a través de estas estrategias se busca que los estudiantes que están en la fase final de su formación académica en la Universidad puedan enfrentarse al mundo 


\begin{tabular}{|c|c|c|}
\hline CUADRO 1 & \multicolumn{2}{|c|}{ Diseño metodológico Proyecto Buen Pastor. Escrito y sonoro } \\
\hline Fase & Estrategia & Producto esperado \\
\hline $\begin{array}{c}\mathbf{1} \\
\text { Reflexión } \\
\text { crítica }\end{array}$ & $\begin{array}{l}\text { Reconocimiento mutuo } \\
\text { Generación de aceptación y } \\
\text { confianza } \\
\text { Roles tradicionales } \\
\text { (estudiante=tutor y reportero } \\
\text { Adolescentes=fuente) }\end{array}$ & $\begin{array}{l}\text { Perfiles sonoros } \\
\text { Perfiles escritos } \\
\text { Fotografías de adolescentes } \\
\text { Videos cortos de integración de tareas }\end{array}$ \\
\hline $\begin{array}{l}2 \\
\text { Intervención } \\
\text { a través de la } \\
\text { acción }\end{array}$ & $\begin{array}{l}\text { Procesos de construcción colectiva } \\
\text { (trabajo colaborativo) } \\
\text { Manejo de fuentes al interior } \\
\text { del Buen Pastor (diferentes de } \\
\text { adolescentes y estudiantes) } \\
\text { Conocimiento de herramientas del } \\
\text { periodismo escrito y televisivo }\end{array}$ & $\begin{array}{l}\text { Periódico Rebien (Boletín de los } \\
\text { adolescentes del Buen Pastor) } \\
\text { Documental: estudiantes y adolescentes } \\
\text { trabajan guión y producción (cámara y } \\
\text { sonido) }\end{array}$ \\
\hline $\begin{array}{l}3 \\
\text { Participación }\end{array}$ & $\begin{array}{l}\text { Los adolescentes “toman el poder" } \\
\text { del proceso; estudiantes son la guía } \\
\text { para implementación con calidad } \\
\text { Preparación y realización de } \\
\text { showroom y de la graduación }\end{array}$ & $\begin{array}{l}\text { Cápsulas sonoras (glosario encapsulado) } \\
\text { Libro de pasatiempos (sopa de letras y } \\
\text { crucigrama) } \\
\text { Showroom: Reflexión sobre cada } \\
\text { experiencia. Preparación de discursos, } \\
\text { orden del día y guion del evento } \\
\text { Presentación combinada de los dos } \\
\text { eventos }\end{array}$ \\
\hline
\end{tabular}

Fuente: Elaboración propia.

real, conociendo antecedentes, contextos y realidades sociales que les permitan desarrollar aprendizajes y destrezas como profesionales comprometidos con la región y el país.

\section{Primera fase: el mutuo reconocimiento}

El reconocimiento mutuo entre los pares (estudiantes y adolescentes) se da en ese primer momento en que el estudiante universitario cumple el papel de periodista y el adolescente infractor el rol de fuente entrevistada. Desde esa idea se desarrolla una estrategia de formación dirigida a estudiantes de Comunicación Social para el desarrollo de las competencias pedagógicas necesarias para la implementación de las actividades contempladas en la estrategia de educomunicación. Así se refiere una estudiante a esos primeros momentos, en la edición de marzo de 2014 del periódico universitario Utópicos. 
En la primera visita al Buen Pastor fuimos un grupo numeroso de estudiantes. Desde el momento en que supe de qué se trataba, no dejé de pensar cómo sería estar ahí en ese lugar, lo imaginé gris y abarrotado, con los adolescentes uniformados y rapados, y aunque ya nos habían mostrado algunas fotos del sitio en la presentación que nos hicieron, no dejé de lado mi imaginario de cárcel de película (Perlaza, 2014: 10-11).

Durante esta primera fase, se desarrollaron tres aspectos importantes:

a. Reconocimiento mutuo

b. Generación de aceptación y confianza

c. Roles tradicionales (Estudiante Universitario = tutor y reportero;

Adolescente infractor $=$ aprendiz y fuente)

Esta pedagogía de trabajo se convierte en un desafío para los estudiantes desde lo educativo, pues en medio de aciertos y dificultades se convierte en un reto de renovación permanente (Posada, Camacho de Argote, Cruz J, Signori, 2007: 2). Así lo manifiestan también algunos estudiantes a través de sus artículos en los que cuentan las vivencias de su experiencia en el proyecto, y que se publicaron en el periódico universitario Utópicos: «Ser capaz de romper la burbuja en la que he vivido toda mi vida, me permitió darme cuenta de mis capacidades para cumplir con los gajes del periodismo» (Muñoz, 2014: 8-9).

Para estos jóvenes universitarios, acostumbrados a hacer simulaciones de trabajos periodísticos, a no correr riesgos y a aprender el 'oficio' manejando fuentes relativamente simples, descubrir el mundo exterior y, sobre todo, volverse partícipes de una actividad transformadora de vidas, ha sido una verdadera experiencia que los marcará para siempre en el ejercicio profesional.

\section{Plan Padrino, ahijados para nunca olvidar}

Como mecanismo para hacer más fácil la tarea de romper el hielo y generar mutua confianza, se diseñó una estrategia que se denominó «Plan Padrino, ahijados para nunca olvidar». Cada uno de los estudiantes universitarios tuvo a cargo a uno de los adolescentes infractores, para guiarlo en el conocimiento de las herramientas del periodismo que se utilizaron. En las primeras semanas, los adolescentes escribieron textos sobre episodios de su infancia, el gusto por los deportes, la música y el entorno familiar. En la primera promoción del taller, al comienzo parecía difícil romper el muro invisible de un pasado violento sobre el que ninguno quería hablar, pero durante las siguientes semanas, las reacciones fueron cambiando.

A través de los primeros escritos de los jóvenes infractores, leídos y corregidos por los estudiantes universitarios, para mejorar el lenguaje y la forma de comunicar, se 
comenzó a fisurar esa muralla. En ese momento se logró confrontarlos con su pasado oscuro, sus episodios de infelicidad en la infancia, los abusos de los que habían sido víctimas, la indiferencia de la sociedad y del Estado; pero especialmente con su visión de futuro: salir del Buen Pastor a cobrar venganza, a aniquilar al enemigo, a seguir buscando el dinero fácil.

A partir de esas experiencias de escritura, se han elaborado varios tomos del libro de perfiles de los adolescentes que se titula «Ahijados para nunca olvidar». Leídos por ellos mismos, meses después de iniciada la experiencia, les causaron vergüenza. También se produjeron perfiles sonoros en los que ellos se pueden escuchar sus voces. En el proceso, manifestaron que se desconocían a sí mismos, evaluaron su manera de hablar, sus frases descarnadas y llenas de odio.

Para escuchar algunos de los perfiles: https://soundcloud.com/ ut-picosusc/perfil-sonoro-1

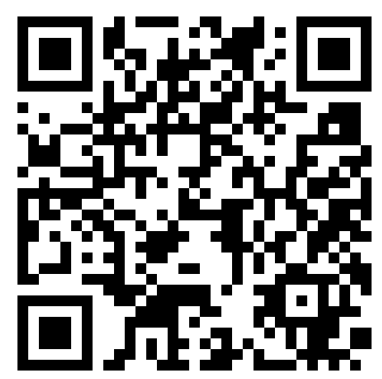

En el caso de los libros de perfiles «Ahijados para nunca olvidar», no se permite compartir lo publicado por protección hacia los menores; sin embargo, se relacionan a continuación algunas imágenes de los tomos.

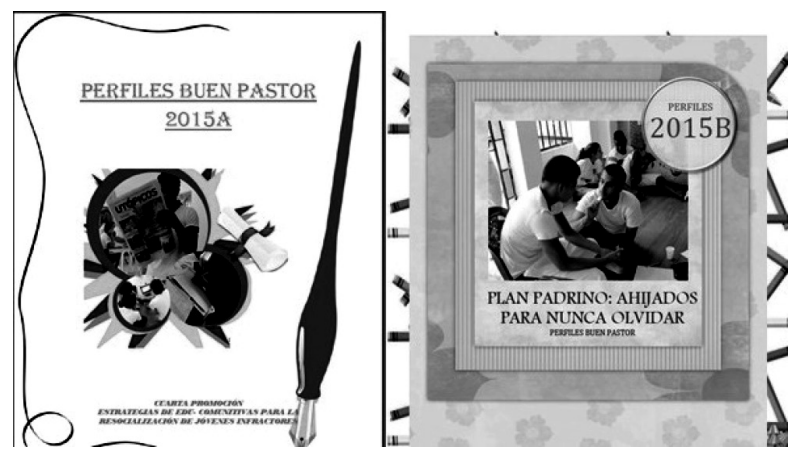

Productos de la estrategia educomunicativa aplicada por el proyecto USC-ONG Crecer en Familia en el CFJ Buen Pastor Cali 
Como lo reseñó el periodista Santiago Cruz Hoyos en el periódico El País de Cali, tras conocer la experiencia y escribir sobre el proyecto:

[...] A través del Plan Padrino, los jóvenes entendieron que sus vidas podrían ser diferentes y que podrían romper el círculo de la violencia en el que se encontraban inmersos. Cuando 'Cejas' y 'H' lo escucharon en la radio, el efecto fue poderoso. Se sorprendieron al oírse, pero al mismo tiempo se avergonzaron. Sus madres los miraron de reojo. Con pena reconocieron que hablaban muy mal, entendieron que en la calle los llaman delincuentes por sus actos; pero también por sus palabras les cierran las puertas en la cara cuando abren la boca. La vergüenza hizo que empezaran a cambiar el lenguaje (Cruz, 2014).

\section{Segunda fase: los adolescentes infractores son los protagonistas y los comunicadores son sus guías}

Tras romper el hielo en el encuentro mutuo de la primera fase, el trabajo colaborativo entre adolescentes y estudiantes afianzó su relación. En los espacios de comunicación planteados se logró trabajar sobre temas periodísticos elegidos por los mismos jóvenes infractores. A la vez se fueron reforzando las técnicas gramaticales, y se establecieron dos líneas de flujo para los trabajos periodísticos. En el periódico Utópicos, se publicaron los contenidos producidos por los estudiantes universitarios, y en el boletín Re bien, los textos escritos por los adolescentes del Centro de Formación. Cabe señalar que el boletín Re bien se diseñó con el ánimo de convertirlo en el espacio natural para que los menores del CFJ publicaran sus artículos y además expresiones artísticas como poemas, dibujos y letras de canciones.

En ese sentido, la segunda fase conjugó una serie de acciones pedagógicas claves que lograron estimular a los chicos en los procesos de construcción colectiva (trabajo colaborativo) de materiales comunicacionales. Para dicha labor los menores debieron aprender sobre el manejo de fuentes en la institución, además del uso de herramientas del periodismo escrito y televisivo. La intervención a través de la acción es el momento cuando se empieza a reconocer el valor de los adolescentes en el quehacer periodístico. Durante esta etapa se trabajaron los siguientes aspectos:

a. Procesos de construcción colectiva (trabajo colaborativo)

b. Manejo de fuentes en el Buen Pastor (diferentes de adolescentes y estudiantes)

c. Conocimiento de herramientas del periodismo escrito y televisivo

d. Posicionamiento del boletín Re bien, como espacio estratégico de divulgación del trabajo de los menores infractores, al interior del CFJ. 

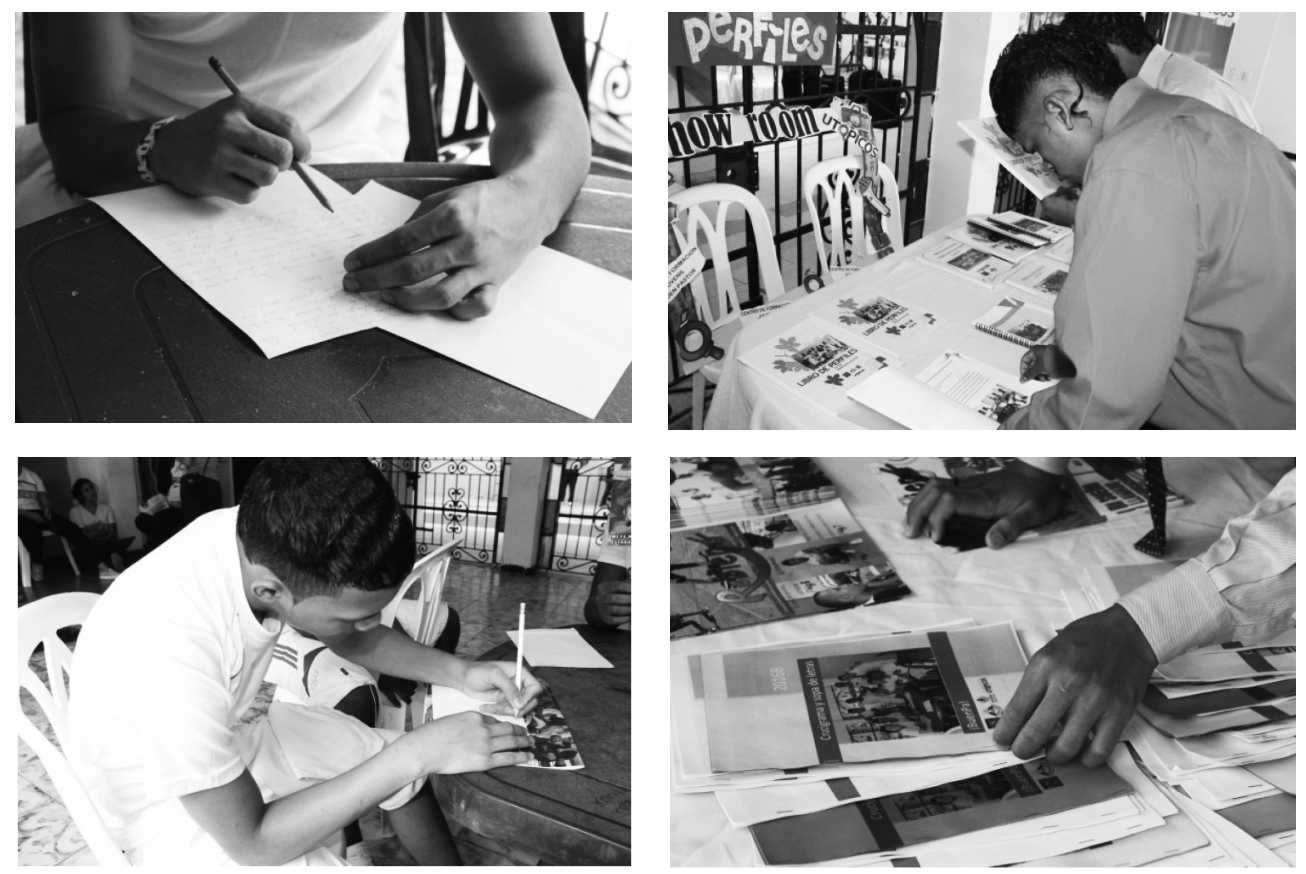

En la medida en que los procesos de construcción colectiva (trabajo colaborativo) empiezan a dar frutos (con productos como textos, materiales audiovisuales y demás), los menores del CFJ, desarrollan el trabajo de realización de un documental que da cuenta de su experiencia en el proceso. Allí, los estudiantes universitarios y los adolescentes del Centro de Formación construyen en conjunto el guión y trabajaron en los procesos de pre, pro y post producción del material, inclusive haciendo cámara y sonido del mismo.

Este momento fue crucial en el proceso de formación de los menores, pues fue un espacio de motivación donde se visibilizó una evolución en el desarrollo del proyecto de resocialización a través de la educomunicación como estrategia, y a la vez una apertura hacia una nueva mirada de la vida por parte de ellos. Esta Intervención a través de la Acción Participativa permitió obtener conocimiento y a la vez construir escenarios de desarrollo.

A partir de esta segunda fase, los menores de cada promoción que pasaron por la experiencia del «Plan Padrino» se graduaron en una ceremonia donde también se presentaron los materiales documentales de cada grupo. En estos se cuentan las vivencias de los jóvenes en el Buen Pastor, cómo transcurren sus días, qué los alienta y qué los hace flaquear. Algunos de ellos recibieron capacitación para ser presentadores y camarógrafos.

A través de los documentales, los adolescentes infractores se reconocieron a sí mismos y también pudieron, por fin, asimilar todo el trabajo que hay detrás para lograr su resocialización. Dentro de este proceso también se aplicó la observación in situ, u observación participante, con el fin de conocer y entender el entorno y de esa manera 
construir las estrategias educomunicativas con base en la cultura y el conocimiento previo de la comunidad participante.

«Una de las características propias de este método, que lo diferencia de todos los demás, es la forma colectiva en que se produce el conocimiento, y la colectivización de ese conocimiento» (Brandao, 1987:18). Como lo menciona este autor, la construcción colectiva transforma la relación entre investigador e investigado, enriqueciendo el proceso de retroalimentación y haciendo que las decisiones tomadas sean más ajustadas a la realidad. Para nuestros estudiantes, ir de la mano de estos jóvenes, enseñándoles lo que han aprendido durante su carrera, permite fortalecer sus vocaciones y encontrar caminos para contribuir al cambio social con herramientas del periodismo y de la comunicación; los empodera y les permite desarrollar de forma impecable la tercera fase.

\section{Tercera fase. Producción de contenidos impresos y graduación de adolescentes talleristas}

En esta etapa, los adolescentes toman el poder del proceso y empiezan a implementar lo aprendido en el Centro de Formación. La participación de los menores contribuye al ejercicio de relevo del poder en el proceso. En ese sentido, es clave el rol de los estudiantes que guían la implementación en esta etapa en que sus ahijados ahora comparten conocimientos con ellos. La preparación y realización de un showroom y de la graduación de los adolescentes como «talleristas en comunicación», ayudan a la reflexión sobre cada experiencia. La preparación de discursos, orden del día y guión del evento, cumplen con el objetivo de visibilizar el proceso educomunicativo. Cabe aquí apelar a la descripción que hace la Unesco de la educomunicación como una estrategia que incluye:

[...] todas las formas de estudiar, aprender y enseñar, a todos los niveles y en toda circunstancia, la historia, la creación, la utilización y la evaluación de los medios de comunicación como artes prácticas y técnicas, así como el lugar que ocupan los medios de comunicación en la sociedad, su repercusión social, las consecuencias de la comunicación mediatizada, la participación, la modificación que producen en el modo de percibir, el papel del trabajo creador y el acceso a los medios de comunicación (Unesco, 1979).

La etapas trabajadas en tercera fase son:

a. Los adolescentes «toman el poder» del proceso y los estudiantes universitarios son la guía para implementar los procesos de producción de medios con calidad.

b. La preparación y realización de un showroom y del evento de graduación, se presentan los materiales realizados y se gradúan los chicos.

c. La producción de documental con los menores del CFJ trabajando como realizadores y productores. 
Cabe señalar que para los estudiantes universitarios el proyecto también ha sido una experiencia pedagógica que les ha permitido confrontarse como profesionales frente al compromiso social de un comunicador. En el caso de los jóvenes universitarios de la carrera de Comunicación de la USC, se resalta el papel que el periódico universitario Utópicos, en sus dos modalidades, impreso y digital, ha jugado en el proceso. Allí se acogen los escritos y las reflexiones de los estudiantes de Comunicación en informes especiales en diferentes géneros, y otras contribuciones como columnas en reportajes, página editorial, crónicas, entrevistas o reportajes gráficos.

Entre diciembre de 2013 y diciembre de 2016 se realizaron 7 talleres con más de 110 adolescentes infractores recluidos en el CFJ Buen Pastor. Para la primera promoción, en 2013, un grupo de estudiantes de Comunicación del proyecto realizó un reportaje llamado «Delincuencia juvenil», en el que investigaron las raíces de la situación crítica que viven adolescentes de bajos recursos en la ciudad de Cali. En una entrevista a uno de los menores del CFJ titulada «Quiero ser comunicador», se expuso la experiencia vivida por los 16 muchachos del Buen Pastor que se graduaron en esa oportunidad como Talleristas en comunicación. El paso por la experiencia educomunicativa generó en ellos un cambio de actitud frente a la vida y una esperanza de progreso tal, que algunos ya sueñan con olvidar su pasado e ingresar a la universidad.

Con el perfil «Un día en el Buen Pastor», se pudo conocer cómo pasa el tiempo de la sanción penal para la mayoría de los 275 internos y cómo hay ahora una luz de esperanza para quienes, como el protagonista de esta historia, Julián Rivera, recuperan la libertad y comprenden que pueden vivir de manera diferente a su pasado. Incluso, episodios difíciles de relatar como el de Miguel, un adolescente que participó en «La Fuga» (una acción desordenada y trágica en la que murieron dos de los jóvenes víctimas del incendio que ellos mismos provocaron) y quien fue recapturado, formaron parte de este especial. No podía faltar «La graduación», una crónica que relata ese momento tan feliz para los 16 adolescentes infractores y para sus familias.

También se puso a prueba el talento de los jóvenes y su capacidad para trabajar en equipo, con la creación del grupo de música urbana "Voces Callejeras", producto de tres meses de un proceso en el que se elaboró una canción que interpretó un nuevo sentimiento hacia el abandono de la violencia y la búsqueda de la reconciliación. Estudiantes y adolescentes infractores escribieron el texto, crearon la música y grabaron el primer disco de los internos.

Cabe explicar que el showroom, concebido como visibilización de la experiencia, incluye la invitación a los familiares de los internos, para que a través de los trabajos de sus jóvenes parientes se concienticen sobre la posibilidad de cambio para sus vidas y entiendan la necesidad de asumir una actitud colaborativa dentro del proceso integral, para el logro de su resocialización. Este cambio actitudinal se refuerza durante la misma jornada, con la ceremonia de graduación, para la cual los adolescentes y estudiantes 
de la USC elaboran el orden del día y participan como maestros de ceremonia, pronuncian discursos preparados previamente y reciben con gran orgullo los diplomas que los acreditan como «Talleristas en comunicación» de la Universidad.

En total, se ha contabilizado una centena de trabajos, entre escritos, audiovisuales y sonoros. Desde hace ya más de tres años, los estudiantes de Comunicación han podido ejercer como verdaderos periodistas y, al mismo tiempo, reconocer la forma como pueden cambiar las vidas de estos jóvenes. ¿Su herramienta?: la comunicación.

Cabe resaltar también el trabajo que desde el comienzo del proyecto, estudiantes universitarios y adolescentes del CFJ, realizaron para la construcción de un glosario que ha ido creciendo con el paso del tiempo. En él se incluyeron palabras técnicas utilizadas por la Ley Penal para Infancia y Adolescencia (por ejemplo, decir «centro de formación» en lugar de cárcel, o «sanción» en vez de sentencia), con el fin de utilizar el léxico apropiado para la vida en sociedad. Este contenido se originó en la búsqueda de la comprensión, por parte de los adolescentes infractores, del hecho de que su inserción en la sociedad pasa no solo por modificar sus conductas, sino también su lenguaje y su forma de actuar. Se incluyen todas las palabras que utilizan en su diario hablar y se realizaron cápsulas sonoras, para fortalecer este importante elemento comunicativo.

La respuesta fue gradual, pero al mismo tiempo radical. Hoy, estos jóvenes han ido modificando sus códigos verbales progresivamente.

Para escuchar algunas cápsulas sonoras: https://soundcloud.com/ ut-picosusc/capsula-1

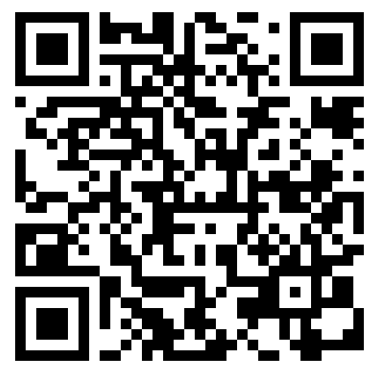

Por tratarse de un estudio de IAP, que por sus característica busca estimular la participación directa de los adolescentes infractores, es posible que en el camino aparezcan apreciaciones y resultados que no se han contemplado inicialmente, lo cual tendrá igualmente validez, pues como sostienen Strauss y Corbin:

«La pregunta original de un estudio cualitativo suele ser amplia y abierta, y tiende a volverse más refinada y específica a medida que progresa la investigación y que van emergiendo los asuntos y problemas del área que se está investigando» (2002: 59). 
Cápsulas
sonoras

Cápsulas
sonoras

Libro de

perfiles
42
Es una pieza radiofónica de corta duración en la que se explora el manejo del lenguaje por parte de los adolescentes y se les motiva a construir nuevas formas de comunicar.
8

Prohibida su distribución sin difuminar las caras de los adolescentes infractores
Es un compendio de perfiles periodísticos de los adolescentes infractores del Centro de Formación Juvenil Buen Pastor que pertenecen al taller 'Plan Padrino'.

\section{Libro de sopa de letras y crucigramas}

2 Libros de crucigramas, 1 libro de sopas de letras
Es un compendio de ejercicios colaborativos entre estudiantes y adolescentes que busca fortalecer las competencias idiomáticas de los adolescentes para facilitar la construcción de contenidos.
Perfiles sonoros 103
Piezas sonoras narrativas que cuentan la vida de los adolescentes infractores, combinadas con música y sonidos ambiente.
Producción audiovisual
5 Documentales, 24 Notas audiovisuales, 5 Videoclips

Prohibida su distribución sin difuminar las caras de los adolescentes infractores.
Documental: pieza audiovisual realizada en trabajo colaborativo entre estudiantes y adolescentes. Tema: reincidentes en el Centro de formación Juvenil Buen Pastor.

Notas audiovisuales: piezas audiovisuales cortas informativas.

Videoclip musical: pieza audiovisual que acompaña o promociona una canción.
615

\section{Registro fotográfico}

Prohibida su distribución sin difuminar las caras de los adolescentes infractores.
Definición: secuencia de imágenes de visitas al Centro de formación Juvenil Buen Pastor.

\section{5}

Revista Rebien
Prohibida su distribución sin difuminar las caras de los adolescentes infractores.
Definición: boletín periodísticos de los adolescentes infractores recluidos en el Centro de Formación juvenil Buen Pastor en colaboración con estudiantes y docentes USC.

\section{Publicaciones en el periódico Utópicos}

Se han realizado tres publicaciones en tres ejemplares diferentes de artículos periodísticos realizados por estudiantes en colaboración con adolescentes infractores del Centro de Formación Juvenil Buen Pastor. 
Este proyecto incluye la reflexión académica de estudiantes que han participado en el Plan Padrino y ahora, a través del Semillero Unimedios-conformado por estudiantes de la línea de profundización en producción de medios-, adelantan sus trabajos de grado como comunicadores, dentro la línea de investigación Comunicación y Educación, donde se maneja el proceso de trabajo con jóvenes del mencionado Centro de Formación.

\section{Conclusiones}

Al presentar esta experiencia, que ha cambiado las vidas -no sólo de los adolescentes infractores sino además de los estudiantes y docentes universitarios- se pretende establecer una ruta para que la experiencia pueda ser replicada. La comunicación es un vehículo óptimo para generar nuevas actitudes y para contribuir a construir un país en paz y democracia.

Y esto podrá ser posible en la medida en que se logre incorporar, a nivel general, a los esquemas de resocialización de adolescentes en Colombia, estrategias que, a partir de la comunicación, enfoquen a los adolescentes en una nueva perspectiva, alejada de la repetición de actos de violencia y más cercana a la construcción de una nueva forma de vida.

Si bien es cierto que algunos adolescentes han manifestado su interés por estudiar comunicación o periodismo una vez culminen la secundaria y egresen del CFJ, el propósito es más ambicioso y se enfoca en construir para ellos un conjunto de herramientas que les permita relacionarse adecuadamente con la sociedad y entender los códigos de comportamiento y respeto que se exigen en la vida cotidiana, laboral y académica.

Por ahora, se puede afirmar que la experiencia ha permitido ubicar la academia en escenarios reales de aprendizaje, facilitando que docentes, estudiantes y comunidad en general se comprometan y configuren otras formas de expresión de ciudadanía. Para el caso de los comunicadores y periodistas en proceso de formación, es fundamental promover en ellos nuevas formas de expresión de ciudadanía a través de su ejercicio profesional como constructores de opinión pública, asumiendo un sentido de responsabilidad social, además de una actitud crítica y ética en relación con el ejercicio periodístico y la responsabilidad de este frente a la ciudadanía.

\section{Bibliografía}

BOREA, J. (2012). La propuesta teórica del periodismo cívico. Correspondenciasy Análisis, 2. Recuperado: http://www.correspondenciasyanalisis.com/es/pdf/cnt/2_propuesta_teorica.pdf

BRANDAO, F. (1987). Investigación Participativa. Montevideo: La Banda Oriental.

HOYOS, S. (2014). «Infractores al aire»: crónica sobre la emisora de El Buen Pastor de Cali. El País. 
EL PAÍS (15 DE ENERO DE 2014). «Cali fue la segunda ciudad con más menores detenidos en Colombia». Disponible en: http://m.elpais.com.co/cali.

MORENO, A. (2006). Otra brújula. Innovaciones en comunicación y desarrollo. Lima: ACS Calandria.

MUÑOZ, A. (2014). La realidad que hay detrás de la burbuja. Explorando un mundo surtido. Utópicos. $6(8), 8$.

PERLAZA, S. (2014). Delincuencia juvenil - quiero ser comunicador. Utópicos.

POSADA, L., CAMACHO, E., CRUZ, V. Y SIGNORI, A. (2007). Pedagogía de la participación en la escuela. España: Instituto de derechos humanos Pedro Arrupe.

ROSEN, J. (1992). No Content: The Press, Politics, and Public Philosophy. Tikkun. 7(3),78. Recuperado: http://datateca.unad.edu.co/contenidos/401110/cotenidonuevo/leccin_36_la_constr uccin_de_lo_ pblico_desde_el_periodismo_cvico.html

VILLABONA, F. (2014). «En busca de los infractores perdidos. Reconstrucción de sentido de vida de un joven privado de la libertad para comprender la crisis del Sistema de Responsabilidad Penal Adolescente colombiano». Manizales: Universidad de Manizales.

ZABALA, M. (s.f.). Investigación acción participación (IAP). Obtenido de Metodologías de la investigación cualitativa: https://icualitativa.wordpress.com/temas/tema-2/investigacion-accion-participacion-iap-marlen-eizagirre-y-nestor-zabala/ 